\title{
Public support for state surveillance
}

\author{
CONRAD ZILLER ${ }^{1}$ iD \& MARC HELBLING ${ }^{2}$ \\ ${ }^{1}$ University of Duisburg-Essen, Germany; ${ }^{2}$ University of Mannheim, Germany
}

\begin{abstract}
This study examines citizens' support for state surveillance, contingent upon factors related to policy design and the context of implementation. While most people want to live in a secure environment, we argue in this study that the support of policies to reach this goal depends on their necessity, extensiveness and reliability. Results from survey experiments in four European countries show that citizens are ready to approve the introduction of far-reaching state surveillance that includes measures of facial recognition and motion detection. Public support is further enhanced if these measures are to be targeted at potential criminals, rather than at all citizens (i.e., policy extensiveness), as well as if a safety threat is salient (i.e., policy necessity). Concerns about data security reduce support (i.e., policy reliability). While these conditions matter for the support of specific policies, they do not influence how trustworthy citizens consider government and other political authorities to be.
\end{abstract}

Keywords: surveillance; political support; terrorism; data security

\section{Introduction}

In the course of recent technical developments, and as a response to security threats such as transnational terrorism, countries around the globe have implemented measures of mass surveillance (Brayne 2014; Epifanio 2011; Graham \& Wood 2003). China, for example, has recently launched a far-reaching social credit system which traces, stores and processes data on the social and economic activities of its roughly 1.4 billion citizens (Liang et al. 2018). In a similar vein, liberal democracies in Western Europe and North America are debating whether or not facial recognition technology should be used to identify criminals. ${ }^{1}$ Against the background of the current outbreak of the COVID-19 disease, one can also expect greater demand for technology that helps detect, register and monitor infected people. ${ }^{2}$

General measures of mass surveillance include CCTV in public places, the interception of electronic communication and the storage and processing of biometric information. These measures are largely intended to prevent terrorist attacks and crime, or, as in the case of a new virus, to control spreading of a disease. Yet at the same time, mass surveillance encroaches on civil liberties and potentially undermines citizens' support for corresponding policies and, more generally, their trust in public authorities. The enforcement of the General Data Protection Regulation in the European Union in 2018 that aims at giving individuals control over their personal data, reflects the importance that is attributed to privacy concerns (Hoofnagle et al. 2019). Mass surveillance might be perceived as a violation of these norms and lead to opposition of such policies.

We know from previous research that people's willingness to accept encroachments on personal freedoms and privacy rights is contingent upon situational factors such as a salient threat (Davis \& Silver 2004; Nelson et al. 1997; Petersen et al. 2011). However, our understanding of the conditions under which citizens support the implementation of surveillance measures remains incomplete 
especially in the face of recent technological developments related to facial recognition and motion detection that enable mass surveillance at larger scales and lower costs than at any point in time before. Moreover, virtually all existing studies have been conducted in the U.S. context (e.g., Davis \& Silver 2004; Dietrich \& Crabtree 2019; Garcia \& Geva 2016).

While the provision of public security constitutes a valence issue, we argue in this study that citizens' support of policies directed at preventing terror and crime depends on the specific scope conditions, namely on policy necessity, extensiveness and reliability. We thus examine how citizens respond to surveillance measures depending on the salience of security-related threats, the range of the policy measure and the risk of violations of data protection. To study these aspects, we conduct survey experiments in Germany, the United Kingdom, France and Spain that randomly assign descriptions of surveillance policies with varying characteristics and thus enable us to causally identify their empirical relevance. While not all policy measures share the feature of being scope dependent, our approach represents an extension of current analytical tools that investigate public support for policies that trade off common goals and individual freedoms. Thus, this study does not only contribute to security studies but to policy research more generally, as we argue and show that the support of policy implementation related to a valence issue (i.e., provision of public security) depends on specific scope conditions.

\section{Surveillance policy implementation and relevant scope conditions}

Scholars of political legitimacy posit that both performance evaluations and normative expectations matter for how citizens perceive the political system (Marien \& Hooghe 2011; Hooghe et al. 2017) even if it is unclear to what extent citizens are able to accurately perceive and assess policy outputs and outcomes (e.g., Campbell 2012; Zaller 1992). According to the distinction between position and valance issues, citizens' policy preferences either refer to an evaluation of alternative political strategies (e.g., restrictive or permissive immigration policy) or to an evaluation of the current states and potential measures for obtaining a widely shared policy goal (e.g., reduction of unemployment). The implementation of political measures in order to prevent crime and terrorism can be seen as a valance issue as these policies have goals that are widely shared in the population (similarly with control of inflation, healthcare or environmental protection). A large majority of the populations in Western democratic societies agrees that their governments should be responsible for these tasks (Roller 2005: 27-33). Moreover, there is also empirical evidence that policy outcomes that mirror government performance with reference to valance issues are strongly related to incumbent party support (Lewis-Beck \& Paldam 2000) and more general evaluations such as political trust (Seyd 2015).

While certain policy goals seem to be widely supported and not achieving them might have political consequences, citizens do not necessarily agree with the means to reach these policy goals (Hooghe et al. 2017). Implementing state surveillance measures might, for example, interfere with democratic ideals of personal freedom and privacy. Looking at the correspondence between citizens' policy preferences (i.e., their normative expectations) and actually implemented laws, we would expect varying policy support depending on whether citizens emphasize freedom and privacy versus security (Davis \& Silver 2004). Hence, public support of surveillance measures is inherently 'scope dependent', which makes it necessary to take the implementation context as well as individual policy preferences into account. 
Moving beyond existing research, we argue that the assessments of valence issues are a direct function of the specific policy implementation context, namely policy necessity, extensiveness and reliability. Regarding the necessity of surveillance, real or perceived threat represents a relevant condition that is directly related to the goal of surveillance policy implementation. In a related vein, security threats appear to be critically relevant to how individuals support counter-terrorist measures (Huddy et al. 2002), and they are also relevant to the degree to which people are ready to give up civil liberties in the name of security (Davis \& Silver 2004; Dietrich \& Crabtree 2019; Garcia \& Geva 2016). Although a few studies find that events such as terror or crime foster perceptions of authorities not being able to ensure safety (Bali 2007; Montalvo 2011), several others instead show that security threats such as terrorism encourage citizens to support incumbent governments (Balcells \& Torrats-Espinosa 2018; Schraff 2020). A motive for this 'rallying behind the flag' lies in citizens' intent to support governments to fix the conditions that led to victimization. A potential avenue for doing so is, for example, the implementation of repressive policies against the source of the threat. Following this line of reasoning, people should be more willing to support state surveillance as proposed by their governments in light of a safety threat, compared to a context where there is no such salient threat.

As for extensiveness, targeted and dragnet (or mass) surveillance measures can be distinguished, where the former focus on a particular suspect individual or group, and the latter involve the collection of information on all members of society. Targeted measures include the introduction of new criminal offences, exceptional procedures for terrorist suspects and constraints on personal freedom such as pre-charge detention and restrictions on movement (Epifanio 2011). Dragnet measures refer to the acquisition of information on communications and movements of people and include CCTV surveillance, number plate recognition systems, as well as biometrics in passports. While dragnet surveillance typically requires greater organizational effort, technological development and decreasing IT costs also reduce the expense of implementing large-scale surveillance. A critical difference between the two types of surveillance pertains to the motives of governments implementing data collection processes. Citizens are likely to expect targeted surveillance to emphasize the provision of (perceived or actual) safety. For dragnet surveillance, the provision of safety may also be anticipated as an underlying motive, but encroachments on the rights of privacy and personal freedoms become more relevant compared to targeted measures. People may be reluctant to support a policy that constricts privacy rights and may perhaps also be suspicious of any government that intends to implement such constrictions. Possible reasons include moral concerns (West \& Bowman 2016), appreciation of autonomy over security (Huddy et al. 2002) and self-interest (Saetnan 2007). We thus expect that -all other things being equalcitizens will be more supportive of surveillance measures if they are targeted rather than dragnet.

As for reliability, the context of data security may influence whether citizens support or disapprove of policy implementation (Aradau \& Blanke 2015). Previous data breaches and leaks have compromised the trustworthiness of companies and political authorities and stimulated public debates about citizens' privacy rights (Martin et al. 2017). Citizens expect authorities to deal with collected data in reliable ways by enforcing privacy rights and cyber security (Braun et al. 2018). While perfect data security is a vain hope, different degrees of anticipated data security exist, and weak data protection can be expected to undermine public support for state surveillance.

While we expect the context of policy implementation to matter for political support in general, we expect conditional treatment effects. Specifically, we argue that a support-eroding effect of dragnet measures is particularly strong if data security is debated, while we expect such an effect 
to be mitigated in the presence of a safety threat. A combination of poor data security and high extensiveness of surveillance should lead citizens to perceive an increasing risk that their own personal information might be subject to a misuse of data. Citizens who thus perceive greater potential harm to their privacy should react with particularly low levels of policy support. We expect public support for dragnet measures to be more widespread in the presence of a safety threat, which primarily justifies state surveillance on a large-scale basis. Another assumption we make is that the negative effect of dragnet policy on political support is mitigated (and the positive effect of targeted measures is increased) when individuals' security preferences are high. Fearful individuals are more likely to change their preferences and to take on more conservative policy preferences (Lerner et al. 2002). According to the definition of terrorism, the aim of these acts is to intimidate a large audience that goes beyond the group of immediate victims. Considering a joint interaction between policy extensiveness, safety threat and security preferences, we expect that the negative effect of dragnet policy (on political support) is mitigated by security threat salience, which is even further mitigated if individuals' security preferences are high.

\section{Data and methods}

To empirically test the stated hypotheses, we conducted a pre-registered factorial survey experiment (https://osf.io/y5zdw/) in Germany in August 2019 and replicated this experiment in France, the United Kingdom and Spain in December 2019. The experiments were embedded in large-scale online public opinion surveys based on samples stratified by gender, age and education in order to match the distribution of the respective country's population (see a detailed sample description in the Online Appendix).

We consider Germany a most likely case regarding the effects of the introduction of state surveillance measures on political support. Due to the elaborate security and surveillance systems that pertained in Nazi Germany and the German Democratic Republic, Germany has a quite unique domestic intelligence structure (i.e., federal and independent state agencies as well as independence from the police) and comparatively extensive regulations on privacy and data protection (Deflem et al. 2018). The majority of the German population opposes data collection on citizens by the government and values the protection of privacy rights (Trepte \& Masur 2017). For these reasons, it can be expected that Germans are highly likely to respond sensitively towards changes in policies related to surveillance.

To point out the extent to which empirical results are generalizable to contexts other than Germany, we replicated the survey experiment in the United Kingdom, France and Spain. These replications were not specified in the pre-registration plan centred on the German case. Nonetheless, the design of the additional experiments matches the pre-registered research design. The rationale of selecting the United Kingdom, France and Spain was to include countries that vary in terms of their previous surveillance laws and public opinion towards surveillance, and thus, to include cases where respondents are less likely to respond to more restrictive surveillance laws than in Germany. In comparison, reports on public opinion data based on the 2016 International Survey Programme (Hiroko 2019) show that for 20 mostly OECD countries, on average, citizens of the United Kingdom and France are among the most tolerant of government surveillance. On the other hand, among the European countries German and Spanish citizens are, on average, much less supportive of governments surveilling their citizens. It can thus be expected that Spaniards, 
similar to Germans, are also very sensitive to surveillance policy changes, whereas this should be less the case for people in France and the United Kingdom.

The factorial experiment design randomly assigned respondents to one of 18 treatment groups, with distinct vignettes manipulating information along the following three dimensions: policy scope (i.e., policy extensiveness; no mentioning of policy scope, dragnet, targeted), data security (i.e., policy reliability; no mentioning of data security, mentioning of data security being discussed, mentioning of data security being at risk), and security threat (i.e., policy necessity; no mentioning of a safety threat, mentioning of the number of country-specific terrorist attacks and victims in the past 3 years). Each respondent read the following basic vignette, which might have been supplemented with additional information, depending on the treatment group to which the respondent was assigned:

Various politicians from governing parties currently want to introduce stricter surveillance laws. Among other things, they include the creation of an information system incorporating data from communications and video surveillance. Data from facial recognition and motion detection techniques are also captured, stored, and processed. ${ }^{3}$

Respondents assigned to the dragnet condition received the following information in their vignette (see Online Appendix Table A.2 for an overview of all vignette dimensions): 'These measures will affect the whole population. [...] The measures do not affect only potential criminals, but all citizens'. Vignettes for respondents in the targeted condition were supplemented by the following: 'These measures concern potential criminals. [...] The measures do not affect all citizens, but only potential criminals'. A mentioning of data security being discussed is reflected in the statement: 'Independent IT specialists have examined these laws and their technical implementation. They are currently discussing how secure the software and data storage are against data theft and cybercrime'. Data security being at risk was manipulated by the statement: 'Independent IT specialists have examined these laws and their technical implementation. They found that the software and data storage are by no means secure against data theft and cybercrime'. The condition of security threat is reflected in the statement: 'There have been four terrorist attacks in Germany since mid-2016, with a death toll of $15{ }^{\prime} .{ }^{4}$ A balance table comparing mean differences of covariates across treatments (see Table A.8 in the Online Appendix) shows no statistically significant mean differences, which indicates that the randomization worked as intended.

As outcome measures, we focus on the specific support of surveillance policy implementation, as well as on political trust in political authorities and institutions reflecting a more abstract form of citizens' support for the political system (for details on item wordings and variable descriptives, see the Online Appendix). The two measures reflect dimensions of citizens' political support that differ in their degree of proximity and allow us to study whether treatment conditions affect policy support only, or also more general views on political authorities. While we expect the two outcomes (specific policy support and general political trust) to be affected in similar directions, we expect to find stronger effects (i.e., higher effect sizes) for specific support compared to political trust due to the different degrees of proximity. Due to the randomization procedure, we are able to identify the causal effect of the various vignette dimensions on the two outcome variables.

To measure preference for security versus freedom, we include two items from the Schwartz' security values dimension, which are collapsed to an index and then dichotomized allowing group comparison (see section on measured variables in the Online Appendix). 


\section{Empirical results}

Looking at respondents over all experimental conditions, the proportion who support the introduction of new surveillance measures (i.e., response above the mid-category of the 11-point answer scales) is 54 per cent in Germany, 59 per cent in Spain, 55 per cent in France and 60 per cent in the United Kingdom. For political trust, about 32 per cent in Germany tend to trust the government, while it is 29 per cent in Spain, 26 per cent in France and 33 per cent in the United Kingdom.

The effects of policy conditions on citizens' policy support are presented in Figure 1. The point estimates indicate how exposure to a specific policy condition lead to more or less approval of the outcome variable compared to the baseline condition (i.e., policy scope not mentioned). Looking at policy support as a dependent variable, we find a unifying pattern across all four countries. The specification that the new surveillance policy implements the collection of data on all residents leads to a minor reduction in policy support when compared to the condition where respondents had no information on the policy scope. However, this effect is negligible in substantial terms (between 0.02 and -0.07 standard deviations, neither being statistically significant). In contrast, framing a targeted scope leads to a pronounced increase in policy support in all four countries (between 0.21 and $0.36 \mathrm{SDs}$ ). An ongoing debate on data security decreases support slightly, while salient concerns about data security reduces support substantially in all four countries (between -0.19 and $-0.37 \mathrm{SDs}$ ). The salience of terrorist attacks strongly predicts higher levels of support for surveillance in all four countries (between 0.26 and 0.48 SDs).

Looking at political trust as a more general form of political support (see Figure 2), we again find a similar pattern of results across the countries included. Neither policy scope nor the salience of data security systematically affects the trust that people place in government. The salience of terrorism as a security threat slightly increases trust in government in Germany, France and the United Kingdom, whereas the effect is statistically significant in Germany only. The differences in statistical significance across countries are likely to be a result of the greater sample size (and power) in the pilot study surveyed in Germany. We nonetheless want to stress that in terms of effect size, effects below 0.2 in standard deviations of the outcome are typically considered as small, notwithstanding statistical significance. Analogously, we find no substantial treatment effects when using trust in other political authorities (e.g., parliament, the legal system, administration and the police) (see Online Appendix Tables A.13-A.16). This suggests that citizens do not consider additional surveillance measures as constituting trust-breaching behaviour on behalf of political authorities. ${ }^{5}$ Concluding from these null findings that political trust is a rather stable trait which is insensitive to policy changes is contradicted by several studies demonstrating political trust to be variant over time and when political events are made salient (Robison \& Mullinix 2016; Ziller \& Helbling 2019). It rather confirms our expectation that treatment effects are stronger for specific policy support than is more general political trust. Moreover, it appears that a highly controversial policy issue such as state surveillance does not necessarily lead to more critical views of the political system.

Finally, we examine the extent to which effects of the policy design are contingent upon data security, salient threat and security orientation as an individual-level characteristic (Figure 3). We show the pattern of results for Germany, but come to similar conclusions for the other three countries included (see Online Appendix Figure A.3). Neither concerns about data security, nor the salience of threat, systematically alter the extent to which people support dragnet or targeted 


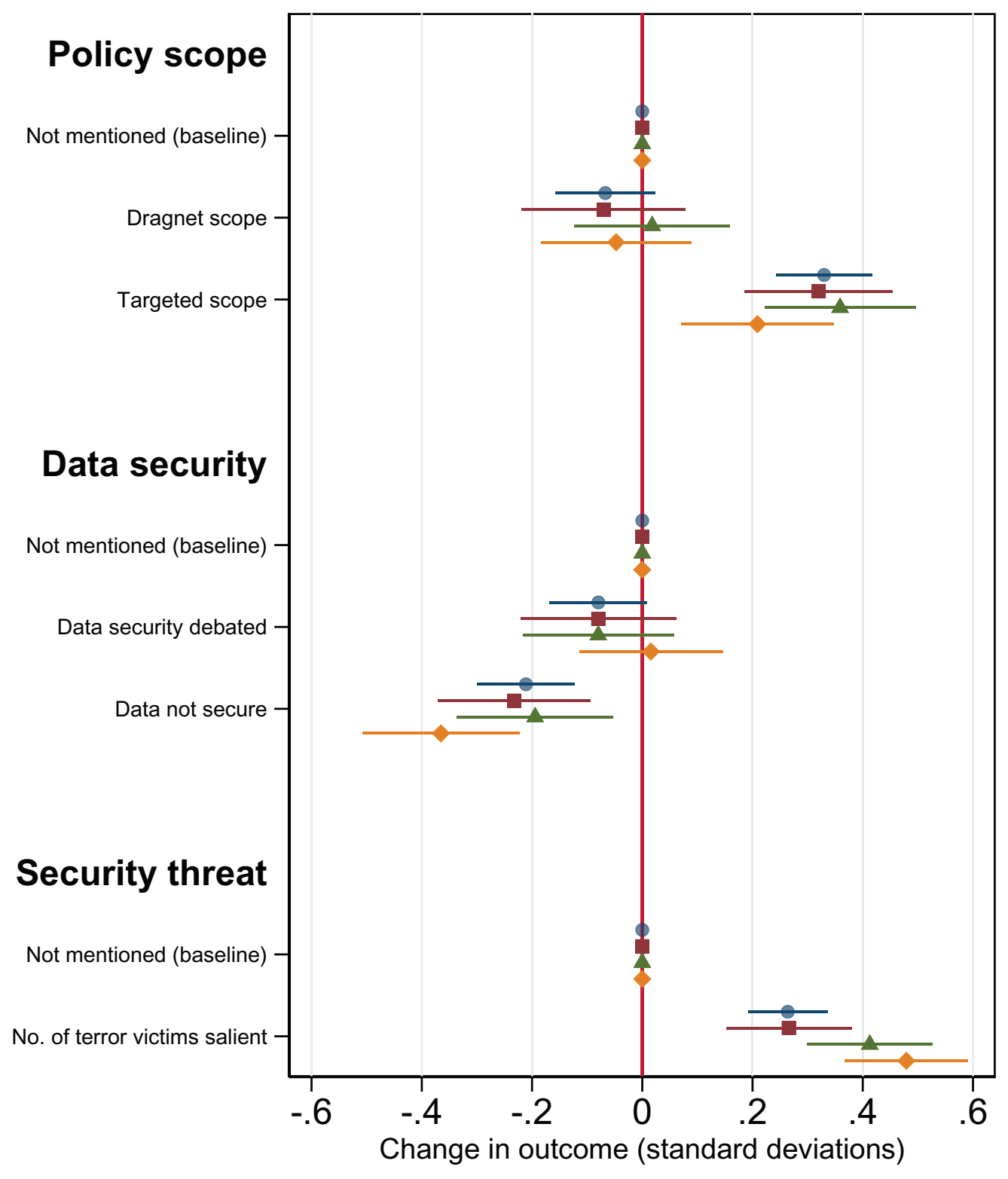

- Germany - Spain $\Delta$ France United Kingdom

Figure 1. Treatment effects of policy specifications on policy support. [Colour figure can be viewed at wileyonlinelibrary.com]

Note: Symbols with horizontal lines indicate point estimates with robust $95 \%$ confidence intervals from linear ordinary least squares regression. The underlying regression results are displayed in Tables A.9-A.12 in the Online Appendix. 


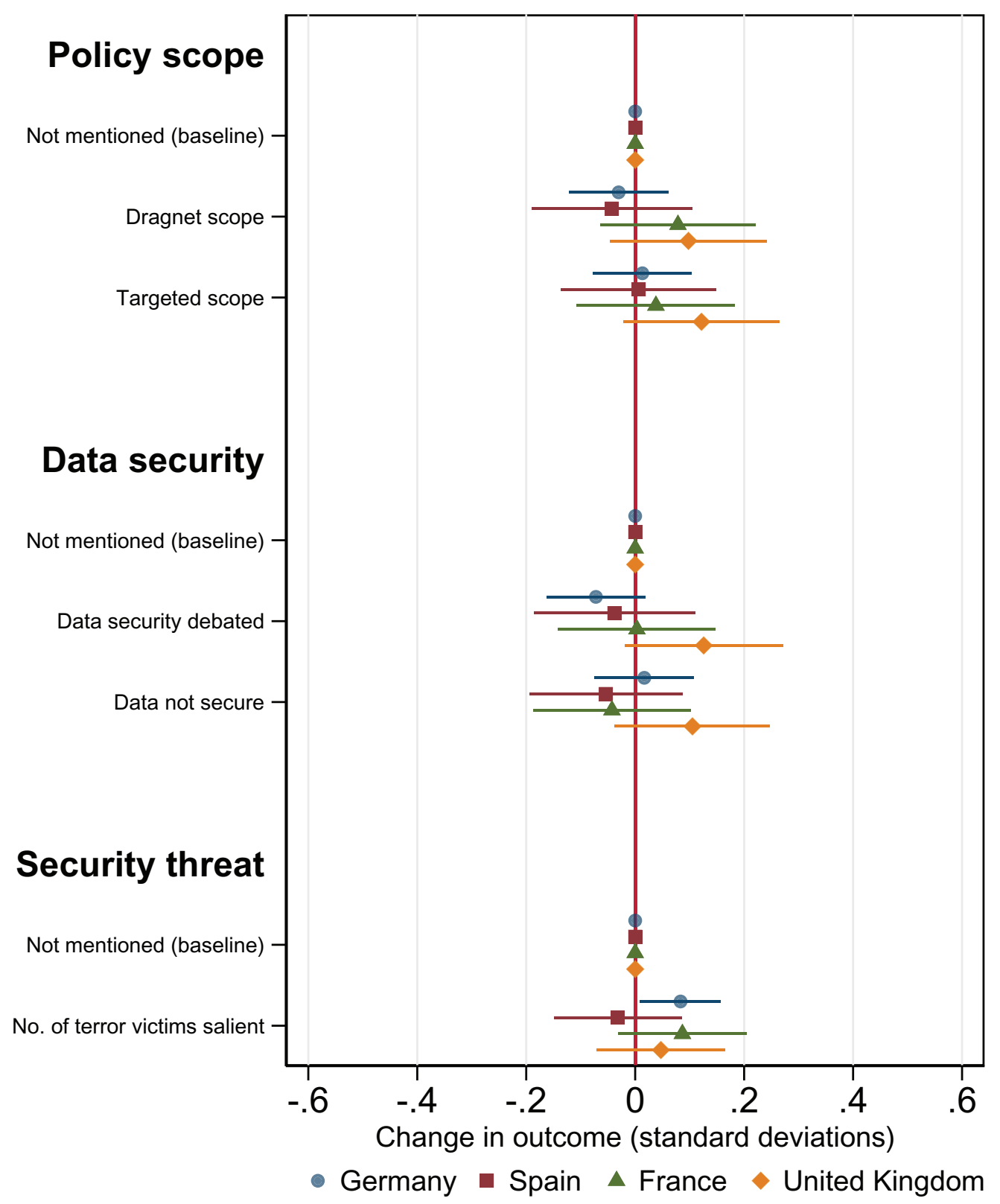

Figure 2. Treatment effects of policy specifications on trust in government. [Colour figure can be viewed at wileyonlinelibrary.com]

Note: Symbols with horizontal lines indicate point estimates with robust $95 \%$ confidence intervals from linear ordinary least squares regression. The underlying regression results are displayed in Tables A.9-A.12 in the Online Appendix. 


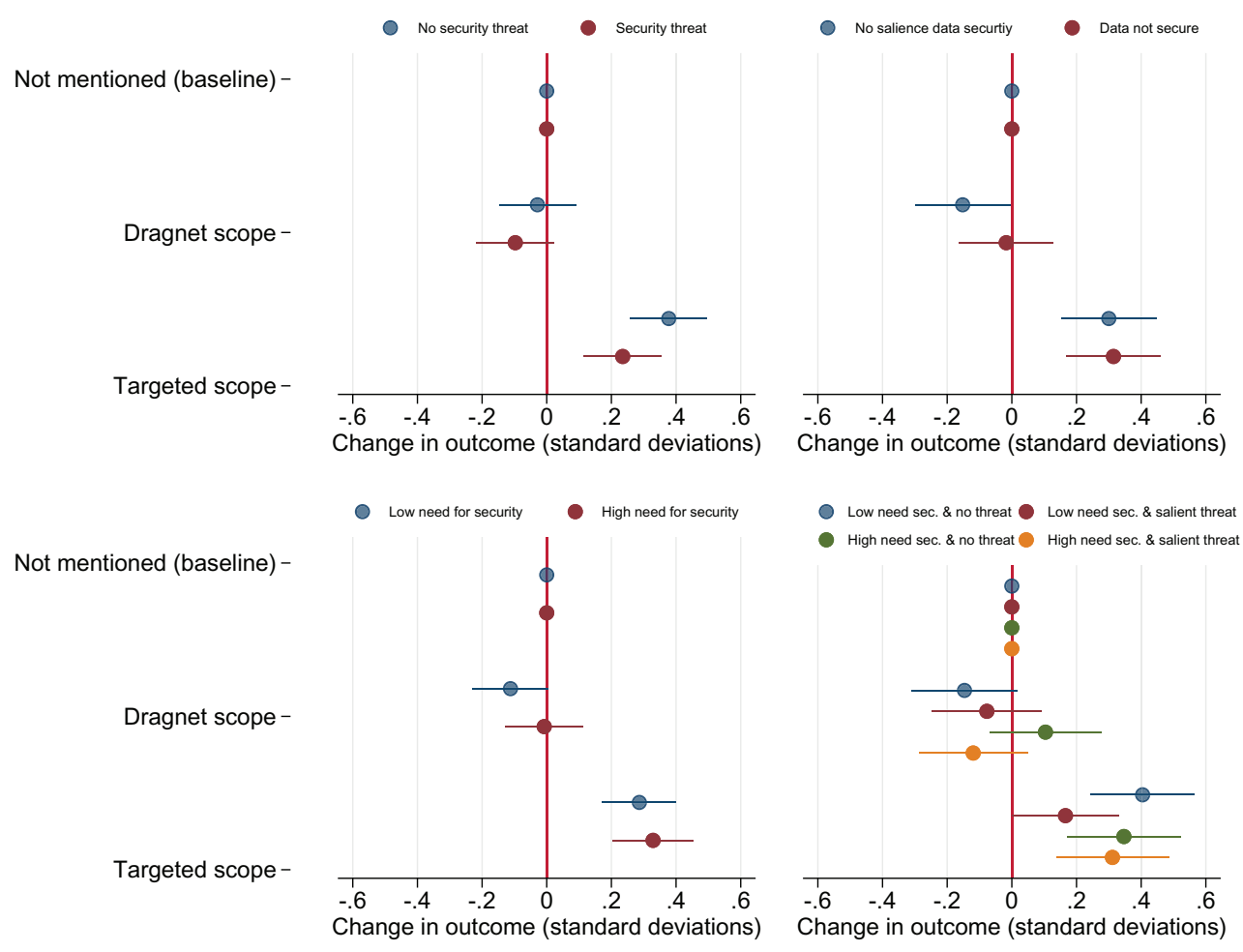

Figure 3. Interactions between policy scope with additional features and individual need for security in Germany. [Colour figure can be viewed at wileyonlinelibrary.com]

Note: Dependent variable is policy support. Estimates are based on regression analysis (ordinary least squares) with heteroscedasticity robust standard errors. Dots represent coefficient estimates, and bars represent $95 \%$ confidence intervals.

measures relative to each other, or to the baseline condition (upper part of Figure 3, neither interaction is statistically significant). People who score low on preference for security tend to express weaker support for dragnet and targeted measures compared to those high in preference for security, although this difference is not statistically significant (lower left part of Figure 3). Combining a security threat and individual preference for security, we find no systematic evidence (i.e., not statistically significant) that these combinations matter in terms of how people respond to specific types of surveillance. When looking at whether these group-specific differences matter for trust in government, we similarly find no evidence of relevant group differences.

\section{Conclusion}

This study sheds light on how people respond to surveillance policies, which is currently a socially and politically highly relevant topic. Governments typically command resources and power to implement far-reaching surveillance measures. Transnational terrorism and criminal activities, and recently the potential of keeping the COVID-19 pandemic at bay via tracking citizens' health status and social interactions, serve as rationales that should legitimize the implementation of surveillance measures. 
Using experimental evidence from four European countries, we demonstrate that citizens are ready to support extensive surveillance measures. This support is substantially conditioned by scope conditions of extensiveness, necessity and reliability. Specifically, we find increased policy support if the surveillance measures are to be targeted at (potential) criminals only, as well as when a security threat is made salient. However, concerns about data security strongly reduced policy support. In short, citizens trade civil liberties for security, but at the same time they are sensitive towards potential data breaches. These scope conditions matter for public support for specific policies, but are hardly relevant for general forms of political support, namely trust in government and other public authorities. The causally identified consequences of surveillance on public support that have been found are strikingly similar in four European countries, despite varying political and institutional characteristics.

Focusing on necessity, extensiveness and reliability as scope conditions of policy support breaks new ground in theoretical terms since much of the policy research literature has been concerned with debates about group-specific versus general policy effects (Jacobs \& Mettler 2018; Schneider \& Ingram 1993), as well as intended versus unintended policy consequences (Adam et al. 2019). Our approach represents a policy-specific framework for the study of policies that trade off common goals and individual freedoms. While not all policy measures fall into that category, policies such as environmental protection policies or social distancing regulations during the current COVID-19 pandemic represent typical cases beyond state surveillance. As for the latter, several recent studies have already investigated how the pandemic and confinement policies affected attitudes towards political institutions in several Western European countries (Bol et al. 2020; Esaiasson et al. 2020; Schraff 2020). We therefore encourage scholars to conduct research applying the presented scope conditions approach using further policy measures.

\section{Acknowledgements}

We want to thank Hans-Jürgen Andreß, Sara Wallace Goodman, Erik Hölzl and Tom Pepinsky for helpful feedback on previous versions of the paper. We also want to thank the editorial team and three anonymous reviewers for valuable suggestions. Conrad Ziller acknowledges funding from the Faculty of Management, Economics and Social Sciences at University of Cologne and the German Research Foundation (ZI 1691/1-1, Project No. 397233023).

Open access funding enabled and organized by Projekt DEAL.

\section{Online Appendix}

Additional supporting information may be found in the Online Appendix section at the end of the article.

Table A.1: Selected newspaper articles on surveillance involving facial recognition and motion detection

Table A.2: Vignette dimensions and levels

Figure A.1: Tests on demographic subgroups

Figure A.2: Main model with respondents who passed attention check only

Figure A.3: Conditional models (Figure 3 in the main text) for other countries

Table A.3: Census and sample characteristics compared - Germany 
Table A.4: Census and sample characteristics compared - Spain

Table A.5: Census and sample characteristics compared - France

Table A.6: Census and sample characteristics compared - United Kingdom

Table A.7: Descriptive statistics

Table A.8: Balance table on mean differences of pre-treatment covariates

Table A.9: Models with and without pre-treatment control variables - Germany

Table A.10: Models with and without pre-treatment control variables - Spain

Table A.11: Models with and without pre-treatment control variables - France

Table A.12: Models with and without pre-treatment control variables - United Kingdom

Table A.13: Models with trust in political authorities as outcome - Germany

Table A.14: Models with trust in political authorities as outcome - Spain

Table A.15: Models with trust in political authorities as outcome - France

Table A.16: Models with trust in political authorities as outcome - United Kingdom

\section{Notes}

1. https://www.theguardian.com/technology/2019/may/22/facial-recognition-prevents-crime-police-tell-ukprivacy-case

2. https://www.berggruen.org/the-worldpost/articles/weekend-roundup-tracking-the-coronavirus-shows-healthwill-trump-privacy/

3. The design of the study was not reviewed by an ethical review board as such a procedure does not exist at the universities of the authors. In order not to mislead respondents or to induce undue anxiety or stress among the respondents, we made the vignettes as realistic as possible and based the text on existing debates on surveillance. Table A.1 in the online appendix provides a selection of newspaper articles that illustrate these debates. At the same time, we speak of 'various politicians from governing parties' to not leave the impression that governments are actually about to introduce new regulations. A potential downside of such a cautious formulation is that these measures are presented as being debated and not decided or implemented, which might potentially attenuate people's responsiveness to the presented vignettes and thus weaken effects on political support. Finally, at the end of the survey we included an attention check that presented the vignettes as a fictitious description of the introduction of a policy measure.

4. This statement has been adapted to the country-specific toll. The numbers are based on a report published by the German Domestic Intelligence Service: https:/www.verfassungsschutz.de/ de/arbeitsfelder/af-islamismus-und-islamistischer-terrorismus/zahlen-und-fakten-islamismus/zuf-is-uebersichtausgewaehlter-islamistisch-terroristischer-anschlaege.

5. As one of the reviewers rightly pointed out, an alternative explanation would be that the vignettes provide no new information (as these measures have already been publicly debated) in order to yield an effect on people's trust. In a related vein, it might be that respondents expected politicians to be discussing these measures prior the experiment. It should also be noted that we speak of 'politicians from government parties' and not the 'government' in the vignettes in order not to mislead the respondents (see note 3). A possible downside of this formulation is that respondents might not have related the policy propositions to their governments.

\section{References}

Adam, C., Hurka, S., Knill, C. \& Steinebach, Y. (2019). Policy accumulation and the democratic responsiveness trap. Cambridge: Cambridge University Press.

Aradau, C. \& Blanke, T. (2015). The (big) data-security assemblage: Knowledge and critique. Big Data \& Society 2(2): 205395171560906. https://doi.org/10.1177/2F2053951715609066.

Balcells, L. \& Torrats-Espinosa, G. (2018). Using a natural experiment to estimate the electoral consequences of terrorist attacks. Proceedings of the National Academy of Sciences 115(42): 10624-10629.

Bali, V. (2007). Terror and elections: Lessons from Spain. Electoral Studies 26: 669-687. 
Bol, D., Giani, M., Blais, A. \& Loewen, P.J. (2020). The effect of COVID-19 lockdowns on political support: Some good news for democracy? European Journal of Political Research online first. https://doi.org/10.1111/1475-6765.12401.

Braun, T., Fung, B.C.M., Iqbal, F. \& Shah, B. (2018). Security and privacy challenges in smart cities. Sustainable Cities and Society 39: 499-507.

Brayne, S. (2014). Surveillance and system avoidance: Criminal justice contact and institutional attachment. American Sociological Review 79(3): 367-391.

Campbell, A.L. (2012). Policy makes mass politics. Annual Review of Political Science 15: 333-351.

Davis, D.W. \& Silver, B.D. (2004) Civil liberties vs. security: Public opinion in the context of the terrorist attacks on America. American Journal of Political Science 48(1): 28-46.

Deflem, M., Silva, D.M.D. \& Rogers, A.S. (2018). Domestic spying: A historical-comparative perspective. In: A. Treviño (ed), The Cambridge Handbook of Social problems. Cambridge: Cambridge University Press, 109-126.

Dietrich, N. \& Crabtree, C. (2019). Domestic demand for human rights: Free speech and the freedom-security trade-off. International Studies Quarterly 63(2): 346-353.

Epifanio, M. (2011). Legislative response to international terrorism. Journal of Peace Research 48(3): 399-411.

Esaiasson, P., Sohlberg, J., Ghersetti, M. \& Johansson, B. (2020). How the coronavirus crisis affects citizen trust in institutions and in unknown others - Evidence from "the Swedish experiment. European Journal of Political Research online first. https://doi.org/10.1111/1475-6765.12419.

Garcia, B.E. \& Geva, N. (2016). Security versus liberty in the context of counterterrorism: An experimental approach. Terrorism and Political Violence 28(1): 30-48.

Graham, S. \& Wood, D. (2003). Digitizing surveillance: Categorization, space, inequality. Critical Social Policy 23(2): 227-248.

Hiroko, M. (2019). State surveillance: How much is too much? Available at https://www3.nhk.or.jp/nhkworld/ en/news/backstories/387.

Hoofnagle, C.J., van der Sloot, B. \& Zuiderveen Borgesius, F. (2019). The European Union general data protection regulation: What it is and what it means. Information \& Communications Technology Law 28(1): 65-98.

Hooghe, M., Marien, S. \& Oser, J. (2017). Great expectations: The effect of democratic ideals on political trust in European democracies. Contemporary Politics 23(2): 214-230.

Huddy, L., Feldman, S., Capelos, T. \& Provost, C. (2002). The consequences of terrorism: Disentangling the effects of personal and national threat. Political Psychology 23(3): 485-509.

Jacobs, L.R. \& Mettler, S. (2018). When and how new policy creates new politics: Examining the feedback effects of the affordable care act on public opinion. Perspectives on Politics 16: 345-363.

Lerner, J.S., Gonzalez, R.M., Small, D.A. \& Fischhoff, B. (2002). Effects of fear and anger on perceived risks of terrorism: A national field experiment. Psychological Science 14: 144-150.

Lewis-Beck, M.S. \& Paldam, M. (2000). Economic voting: An introduction. Electoral Studies 19(2): 113-121.

Liang, F., Das, V., Kostyuk, N. \& Hussain, M.M. (2018). Constructing a data-driven society: China's social credit system as a state surveillance infrastructure. Policy \& Internet 10(4): 415-453.

Marien, S. \& Hooghe, M. (2011). Does political trust matter? An empirical investigation into the relation between political trust and support for law compliance. European Journal of Political Research 50(2): 267-291.

Martin, K.D., Borah, A. \& Palmatier, R.W. (2017). Data privacy: Effects on customer and firm performance. Journal of Marketing 81(1): 36-58.

Montalvo, J.G. (2011). Voting after the bombings: A natural experiment on the effect of terrorist attacks on democratic elections. Review of Economics and Statistics 93: 1146-1154.

Nelson, T.E., Clawson, R.A. \& Oxley, Z.M. (1997). Media framing of a civil liberties conflict and its effect on tolerance. American Political Science Review 91(3): 567-583.

Petersen, M., Slothuus, R., Stubager, R. \& Togeby, L. (2011). Freedom for all? The strength and limits of political tolerance. British Journal of Political Science 41(3): 581-597.

Robison, J. \& Mullinix, K.J. (2016). Elite polarization and public opinion: How polarization is communicated and its effects. Political Communication 33(2): 261-282.

Roller, E. (2005). The performance of democracies: Political institutions and public policy. Oxford: Oxford University Press.

Saetnan, A.R. (2007). Nothing to hide, nothing to fear? Assessing technologies for diagnosis of security risks. International Criminal Justice Review 17(3): 193-206. 
Schneider, A. \& Ingram, H. (1993). Social construction of target populations: Implications for politics and policy. American Political Science Review 87: 334-347.

Schraff, D. (2020). Political trust during the Covid-19 pandemic: Rally around the flag or lockdown effects? SocArXiv, 8 June 2020. https://doi.org/10.31235/osf.io/pu47c.

Seyd, B. (2015). How do citizens evaluate public officials? The role of performance and expectations on political trust. Political Studies 63: 73-90.

Trepte, S. \& Masur, P.K. (2017). Privacy attitudes, perceptions, and behaviors of the German population: Research Report. In: M. Friedwald et al. (eds.), Forum Privatheit und selbstbestimmtes Leben in der digitalen Welt. Karlsruhe: Fraunhofer, ISI. Available at http://www.philippmasur.de/documents/pubs/Trepte_Masur_ 2017_Research_Report_Hohenheim.pdf.

West, J.P. \& Bowman, J.S. (2016). The domestic use of drones: An ethical analysis of surveillance issues. Public Administration Review 76(4): 649-659.

Zaller, J.R. (1992). The nature and origins of mass opinion. Cambridge: Cambridge University Press.

Ziller, C. \& Helbling, M. (2019). Antidiscrimination laws, policy knowledge and political support. British Journal of Political Science 49(3): 1027-1044.

Address for correspondence: Conrad Ziller, Working Group of Empirical Political Science, Department of Political Science, University of Duisburg-Essen, 47057 Duisburg, Germany. Email: conrad.ziller@uni-due.de 